\title{
Sclerostin neutralization unleashes the osteoanabolic effects of Dkk1 inhibition
}

\author{
Phillip C. Witcher, ${ }^{1}$ Sara E. Miner, ${ }^{1}$ Daniel J. Horan, ${ }^{1}$ Whitney A. Bullock, ${ }^{1}$ Kyung-Eun Lim, ${ }^{1}$ \\ Kyung Shin Kang, ${ }^{1,2}$ Alison L. Adaniya, ${ }^{1}$ Ryan D. Ross, ${ }^{3}$ Cabriela G. Loots, ${ }^{4,5}$ \\ and Alexander G. Robling ${ }^{1,6,7,8}$ \\ 1Department of Anatomy \& Cell Biology, Indiana University School of Medicine, Indianapolis, Indiana, USA. ${ }^{2}$ Department \\ of Physical Sciences \& Engineering, Anderson University, Anderson, Indiana, USA. ${ }^{3}$ Department of Cell \& Molecular \\ Medicine, Rush University Medical Center, Chicago, Illinois, USA. ${ }^{4}$ Biology and Biotechnology Division, Lawrence Livermore \\ National Laboratory, Livermore, California, USA. ${ }^{5}$ School of Natural Sciences, University of California, Merced, California, \\ USA. ${ }^{6}$ Richard L. Roudebush Veterans Affairs Medical Center, Indianapolis, Indiana, USA. ${ }^{7}$ Department of Biomedical \\ Engineering, Indiana University-Purdue University Indianapolis, Indianapolis, Indiana, USA. ${ }^{8}$ Indiana Center for \\ Musculoskeletal Health, Indianapolis, Indiana, USA.
}

The WNT pathway has become an attractive target for skeletal therapies. High-bonemass phenotypes in patients with loss-of-function mutations in the LRP5/6 inhibitor Sost (sclerosteosis), or in its downstream enhancer region (van Buchem disease), highlight the utility of targeting Sost/sclerostin to improve bone properties. Sclerostin-neutralizing antibody is highly osteoanabolic in animal models and in human clinical trials, but antibody-based inhibition of another potent LRP5/6 antagonist, Dkk1, is largely inefficacious for building bone in the unperturbed adult skeleton. Here, we show that conditional deletion of Dkk1 from bone also has negligible effects on bone mass. Dkk1 inhibition increases Sost expression, suggesting a potential compensatory mechanism that might explain why Dkk1 suppression lacks anabolic action. To test this concept, we deleted Sost from osteocytes in, or administered sclerostin neutralizing antibody to, mice with a Dkk1-deficient skeleton. A robust anabolic response to Dkk1 deletion was manifest only when Sost/sclerostin was impaired. Whole-body DXA scans, $\mu$ CT measurements of the femur and spine, histomorphometric measures of femoral bone formation rates, and biomechanical properties of whole bones confirmed the anabolic potential of Dkk1 inhibition in the absence of sclerostin. Further, combined administration of sclerostin and Dkk1 antibody in WT mice produced a synergistic effect on bone gain that greatly exceeded individual or additive effects of the therapies, confirming the therapeutic potential of inhibiting multiple WNT antagonists for skeletal health. In conclusion, the osteoanabolic effects of Dkk1 inhibition can be realized if sclerostin upregulation is prevented. Anabolic therapies for patients with low bone mass might benefit from a strategy that accounts for the compensatory milieu of WNT inhibitors in bone tissue.

Conflict of interest: The authors have declared that no conflict of interest exists.

Submitted: November 14, 2017 Accepted: April 26, 2018 Published: June 7, 2018

Reference information: JCI Insight. 2018;3(11):e98673. https://doi.org/10.1172/jci. insight. 98673.

\section{Introduction}

The WNT signaling pathway has important functions in skeletal metabolism. Low-bone-mass phenotypes (e.g., osteoporosis-pseudoglioma syndrome [OPPG], OMIM 259770) observed in patients with loss-offunction mutations in a coreceptor for WNT, LDL receptor-related protein 5 (LRP5) (1-3), and high-bonemass (HBM) phenotypes (e.g., endosteal hyperosteosis, OMIM 144750) observed in patients with gainof-function mutations in LRP5 (4-7) both highlight the prominent role that WNT/LRP5 signaling plays in the skeleton. A particularly attractive attribute of the WNT pathway is its effects on anabolic action in bone; consequently, harnessing this pathway to improve skeletal properties in patients with low bone mass represents a major area of investigation for the pharmaceuticals development field.

The anabolic nature of WNT action in bone has been further highlighted by studies focused on the bone overgrowth phenotype among patients with loss-of-function mutations in the SOST gene (sclerosteosis, OMIM 269500), whose protein product, sclerostin, is a potent negative regulator of LRP5 signaling. Sclerostin inhibits LRP 5 by directly binding the first $\beta$-propeller of LRP 5 , which disrupts interaction with the WNT1 class of ligands (8). Genetic disruption $(9,10)$ or transgenic overexpression $(11,12)$ of Sost in mice results in increased 
or decreased bone mass, respectively, which is largely driven by changes in bone formation rate. Further, sclerostin-neutralizing antibodies have dramatic and consistent bone-building effects in mice (13-15), rats (16-18), monkeys $(19,20)$, and humans $(21,22)$, leading to significant improvement in bone mass, strength, and fracture susceptibility. These experiments and clinical trials attest to the therapeutic value of targeting sclerostin for improving skeletal properties.

Targeting other secreted inhibitors of WNT signaling that normally disrupt the WNT-LRP5 interaction has appeared less promising for general treatment of low bone mass. For example, the secreted LRP5/6 antagonist Dkk1 is a potent inhibitor of WNT signaling in cultured bone cells (23-25), binding directly to the first and third $\beta$-propellers of LRP5/ 6 and disrupting interaction with WNT1- and WNT3-class ligands (26). Homozygous inactivation of Dkk1 in mice is perinatal lethal, but Dkk1 haploinsufficiency $\left(D k k 1^{+/-}\right)$ (27) and/or hypomorphic mutation (e.g., doubleridge) (28) results in increased bone mass (29). However, pharmacologic blockade of Dkk1 in rats and mice via neutralizing antibody is only mildly efficacious in young animals and is largely ineffective at improving bone mass in adult animals (30). In light of the strong anabolic effects of sclerostin neutralization, this is a puzzling finding given that Dkk1 is such a potent inhibitor of the WNT-LRP5/6 interaction; at equimolar concentration Dkk1 outcompetes sclerostin for binding to LRP5 and can even displace pre-bound sclerostin from LRP5 receptors (31). Why, then, is Dkk1 neutralization not more anabolic for bone?

We sought to investigate whether we could unlock fuller anabolic potential of Dkk1 neutralization by trying first to better understand the auxiliary molecular events caused by Dkk1 inhibition that might negate its otherwise osteoanabolic effects. Data from human patients with sclerosteosis (32) and from mice treated with sclerostin antibody $(33,34)$ indicate that sclerostin deficiency results in an increase in Dkk1 protein levels. We investigated whether the opposite compensatory mechanism exists (i.e., Dkk1 deficiency modulates sclerostin levels) and whether this could account for the lack of efficacy of Dkk1 inhibition. Using global and bone-selective Sost- and Dkk1-deficient mouse models, in conjunction with neutralizing antibodies to both proteins, the functional studies performed strongly suggest that Dkk1 neutralization is potently anabolic to bone tissue if the compensatory upregulation of sclerostin is neutralized.

\section{Results}

Mice with bone-selective deletion of Dkk1 or WT mice treated with Dkk1-neutralizing antibody exhibit a mild bone phenotype. The skeletal consequences of Sost genetic disturbances have been widely studied in mice (9, $10,13)$ and humans $(35-37)$, but less is known about the effects of Dkk1 loss - another potent inhibitor of LRP5/6. To understand the magnitude of the potential HBM phenotype generated by Dkk1 deletion in bone, while avoiding the lethal phenotype observed in global Dkk1-knockout mice (27), we bred mice harboring Dkk1 floxed loss-of-function alleles to the ${ }^{10 \mathrm{~kb}} \mathrm{Dmp} 1-\mathrm{Cre}$ driver strain and quantified the phenotype radiographically. Presence of the ${ }^{10 \mathrm{~kb}} \mathrm{Dmp} 1-C r e$ allele reduced Dkk1 expression by more than $80 \%$ in cortical bone lysates from $D k k^{f l / f l}$ mice (Supplemental Figure 1; supplemental material available online with this article; https://doi.org/10.1172/jci.insight.98673DS1). Serial dual-energy x-ray absorptiometry (DXA) revealed a slight but significant increase in whole-body bone mineral content (BMC) among Cre-positive females $(12 \%$ increase, $P<0.05)$ but not males compared with their respective Cre-negative $D k k 1^{f l f f}$ littermates (Figure 1, A and B). Cancellous bone volume fraction at 16 weeks of age was $6 \%$ greater $(P<0.05)$ among Cre-positive compared with Cre-negative females, but Cre-positive males did not exhibit a significant difference from Cre-negative male controls (Figure 1, C and D). Given previous findings of altered matrix composition in LRP5 and Sost mutant mice $(38,39)$, we also examined bone chemical properties in the conditional Dkk1 mutant mice using Fourier transform infrared imaging (FTIRI). No changes in matrix properties were found when Dkk1 was deleted from bone (Supplemental Figure 2)

To assess whether the surprising absence of a robust HBM phenotype in mice with late-stage bone cell deletion (i.e., in Dmp1-expressing cells) of Dkk1 was perhaps the result of our failure to target the appropriate cell type (e.g., cells earlier in the lineage), we next inhibited Dkk1 more broadly by administering a Dkk1-neutralizing antibody to 10-week-old WT mice. Six weeks of treatment with Dkk1 antibody (25 mg/ $\mathrm{kg}$ s.c., twice a week) did not significantly change DXA-derived whole-body BMC when compared with vehicle treatment, in either males or females, but a small but significant increase $(11 \%, P<0.05)$ in BMC as measured by peripheral quantitative $\mathrm{CT}(\mathrm{pQCT})$ at the proximal tibia was detected among antibody-treated females (Figure 1, E and F). In summary, neither bone-selective deletion of the Dkk1 gene nor systemic inhibition of extracellular Dkk1 protein increased bone mass consistently or to the extent seen in other 

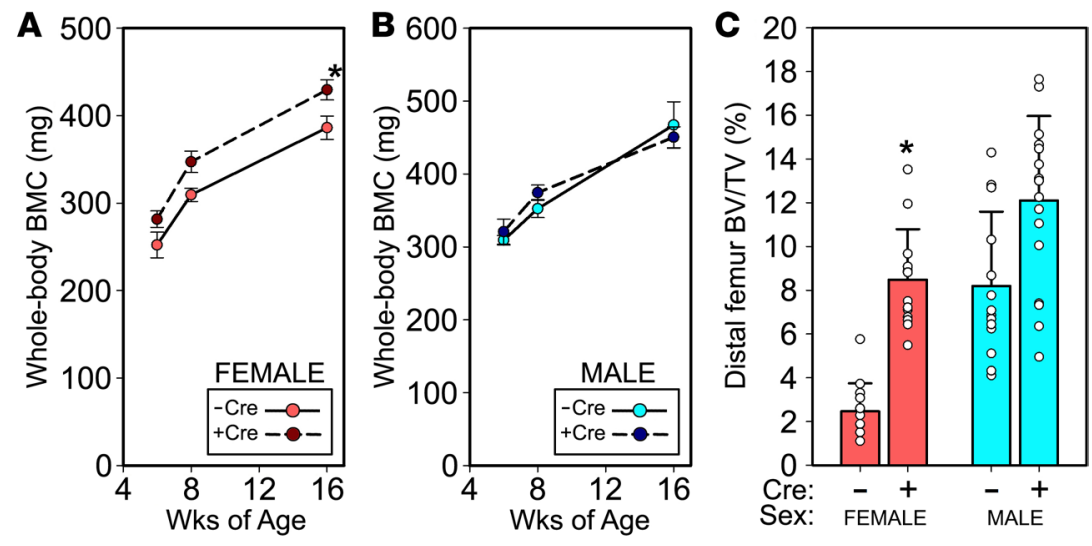

D

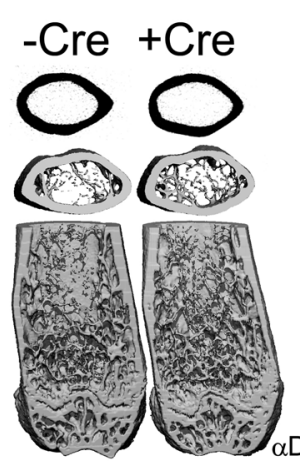

E

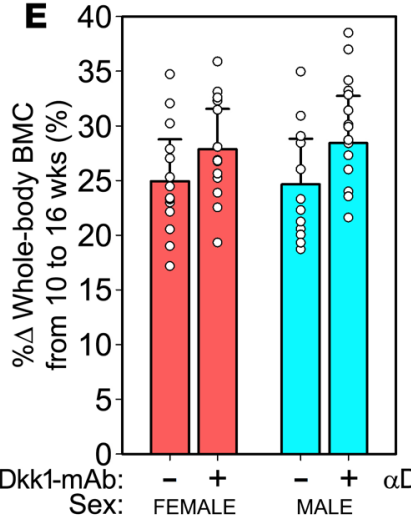

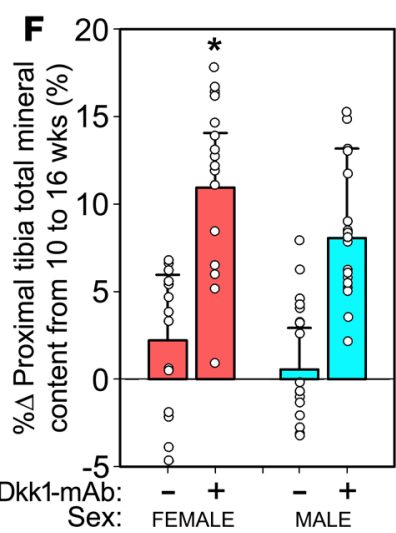

Figure 1. Conditional deletion of Dkk1 from bone cells or antibody-induced systemic neutralization of Dkk1 in WT mice has minor effects on the skeleton. ( $A$ and B) Longitudinal dual-energy $x$-ray absorptiometryderived (DXA-derived) measures of whole-body bone mineral content (BMC) in (A) female and (B) male mice carrying homozygous floxed loss-of-function alleles for Dkk1, with (+Cre) or without (-Cre) the ${ }^{10 \mathrm{~kb}} \mathrm{Dmp1}$-Cre transgene. (C and $\mathbf{D}) \mu \mathrm{CT}$-derived measurements of bone volume fraction in the distal femur secondary spongiosa (C) and representative 3D tomographic reconstructions of the distal and midshaft femur (images shown represent female mice) (D) from $D k k 7^{\text {fl/fl }}$ mice with or without the ${ }^{10 \mathrm{~kb}} \mathrm{Dmp1}$-Cre transgene. (E and $\mathbf{F})$ Percent change (from before to after treatment) in DXA-derived whole-body BMC (E) and peripheral quantitative CT-derived total mineral content at the proximal tibia (F) in male and female WT mice treated for 6 weeks with Dkk1 neutralizing antibody ( $\alpha$ Dkk1-mAb) or vehicle control. ${ }^{*} P<0.05$ compared with sex-matched control mice. For all experiments, $n=11-15$ mice/group. Data in A and $\mathbf{B}$ were analyzed using repeated-measures ANOVA followed by Fisher's protected LSD post hoc tests. Data in C, E, and $\mathbf{F}$ were analyzed using 1-way ANOVA followed by Fisher's protected LSD post hoc tests.

WNT pathway mutants (e.g., LRP5 HBM models, Sost models, LRP4 models) (9, 40, 41) and/or pharmacologic inhibition models (e.g., sclerostin neutralization) $(13,16)$.

Dkk1 levels and/or bioavailability regulate Sost - a potential override mechanism of Dkk1-mediated control of bone metabolism. Previous reports in mice $(33,42)$ and humans $(32)$ indicate that Dkk1 expression is modulated by perturbations in Sost/sclerostin expression. We sought to address the reciprocal situation, to understand whether Sost expression is modulated by Dkk1 perturbation. In particular, we asked whether Sost expression increases in response to Dkk1 deletion or inhibition; and whether this potential mechanism might explain the failure of Dkk1 inhibition/deletion to have robust bone building effects on the skeleton. Mice heterozygous for a LacZ reporter allele knocked into the Sost coding sequence (Sost ${ }^{+/ L a c Z}$ mice) were injected with a single $25-\mathrm{mg} / \mathrm{kg}$ dose of Dkk1 antibody. Two days later, the mice were sacrificed and the femurs dissected, cryosectioned, and stained for LacZ expression. Dkk1 protein neutralization resulted in a qualitative increase in Sost reporter activity in the bone tissue (Figure 2, $\mathrm{A}$ and $\mathrm{B})$. Additional, quantitative gene expression experiments were performed using cortical bone lysates from WT mice treated with Dkk1 antibody; from mice with bone-selective deletion of Dkk1; and from transgenic ${ }^{2.3 k b}$ Col1a1-Dkk1 mice, which overexpress Dkk1 in bone tissue (Supplemental Figure 1). Bone-selective deletion of $\mathrm{Dkk} 1$ and antibody-mediated neutralization of Dkk1 protein produced a significant increase in Sost expression (Figure 2C). In summary, Dkk1 protein neutralization or genetic deletion from bone resulted in a compensatory increase in Sost expression, which might explain the inefficacy of Dkk1 inhibition in improving bone properties.

Bone-selective deletion of Dkk1 consistently and robustly improves bone mass when Sost is co-deleted from the same cell population. In light of the compensatory upregulation of Sost that occurs when Dkk1 is inhibited or mutated, we next tested whether Sost induction was responsible for the meager skeletal effects of bone-selective Dkk1 deletion. Our goal was to determine whether Dkk1 deletion from bone could have a more consistent and robust effect on bone mass if the compensatory increase in Sost expression were prevented. To this end, we generated compound mutant mice with floxed loss-of-function alleles for Dkk1, with or without co-deletion of Sost in the same cells (i.e., Sost $t^{f / f l}$ mice). The Sost conditional mice have a floxed conditional by inversion (COIN) module targeted to the single intron of Sost, which undergoes inversion upon 

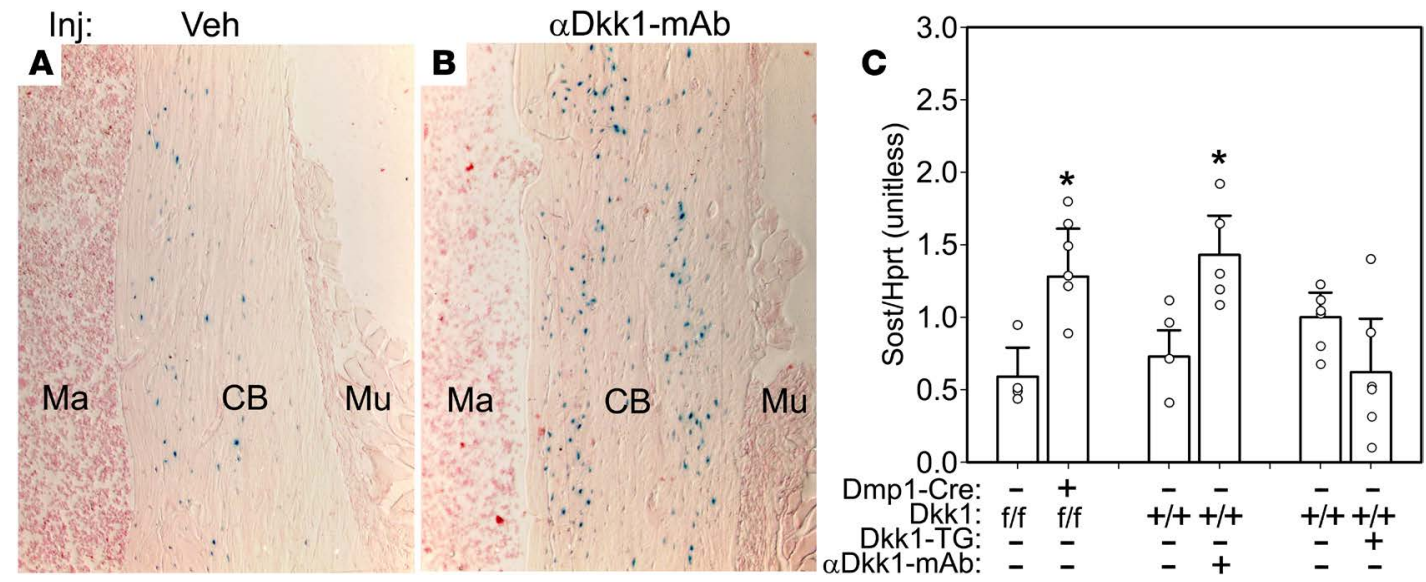

Figure 2. Genetically disabling or pharmacologically inhibiting Dkk1 increases Sost expression. (A and B) Representative photomicrographs of $\beta$-galactosidase-reacted frozen sections cut from the thigh of female mice heterozygous for a Sost-knockin reporter allele (Sost ${ }^{+/ L a c z}$ ). Mice were given a single injection of vehicle (Veh; A) or Dkk1-neutralizing antibody ( $\alpha$ Dkk1-mAb; B) 2 days prior to sacrifice. Blue staining in the cortical bone (CB) indicates endogenous Sost promoter activity. Mu, muscle; Ma, marrow. (C) Quantitative PCR of Sost transcripts in femoral and tibial cortical bone from female mice with conditional ( ${ }^{10 k b} \mathrm{Dmp1}$-Cre-mediated) homozygous inactivation of Dkk1 (left), from WT mice treated with $\alpha$ Dkk1-mAb (center), and from ${ }^{2.3 k b}$ Col1a1-Dkk1 mice overexpressing Dkk1 in bone tissue (Dkk1-TC; right). ${ }^{*} P<0.05$ compared with corresponding controls. $n=4-7$ mice/group. Data in C were analyzed using 1-way ANOVA followed by Fisher's protected LSD post hoc tests.

Cre-mediated recombination (43). Again, we used the ${ }^{10 \mathrm{~kb}} \mathrm{Dmp} 1-\mathrm{Cre}$ driver strain to induce recombination, and we included Cre-negative controls for all Sost/Dkk1 genotypes studied. Mice were scanned periodically using DXA from 4 to 16 weeks of age. Body weight was similar among sex-matched mice regardless of the presence of Cre or Sost/Dkk1 alleles (Supplemental Figure 3), and no significant differences in DXA properties were detected among Cre-negative control Sost/Dkk1 genotypes (Figure 3, A, C, and E; and Supplemental Figure 4). Among Cre-positive female mice, BMC was not significantly different between Dkk1 mutants and WT controls, but Sost mutants exhibited a significant increase in BMC compared with both WT mice (13\%-29\% increase, $P<0.05)$ and Dkk1 mutants $(10 \%-26 \%$ increase, $P<0.05$; Figure 3 , $\mathrm{B}, \mathrm{D}$, and F). Surprisingly, whereas Dkk1 deletion from bone had no effect on BMC in Sost-replete mice, Dkk1 deletion in mice that underwent co-deletion of Sost in the same cells exhibited very large increases in whole-body BMC compared with both WT mice $(24 \%-75 \%$ increase, $P<0.05)$ and Sost mutant mice (10\%-36\% increase, $P<0.05)$. Male mice showed similar genotype effects, with the exception of the Dkk1 mutants, which exhibited significantly elevated hindlimb BMC (Supplemental Figure 4)

$\mu \mathrm{CT}$ measurements collected from the spine and femur of these mice (16 weeks of age) revealed an even more striking HBM-generating effect of Dkk1 deletion in the presence of Sost co-deletion (Figure 4). Bone volume fraction in the fifth lumbar vertebral $\left(\mathrm{L}_{5}\right)$ spongiosa was significantly increased in male and female Dkk1 mutant mice (increases of $7 \%$ and $12 \%$, respectively; $P<0.05$ for both) compared with WT mice (Figure 4, A-C and Supplemental Figure 5). Sost mutant mice exhibited 35\% and 27\% increases over WT controls in $\mathrm{L}_{5}$ trabecular bone volume fraction (BV/TV) among male and female mice, respectively ( $P$ $<0.05$ for both). Dkk1 deletion in mice that underwent co-deletion of Sost exhibited a very large increase in $\mathrm{L}_{5} \mathrm{BV} / \mathrm{TV}$, reaching $70 \%-80 \%(P<0.05)$ beyond that in WT mice and $\sim 45 \%(P<0.05)$ beyond that in Sost mutant mice. Similar effects were found for other $\mu \mathrm{CT}$ measurements from the distal femur cancellous envelope (Figure 4, D-F, and Supplemental Figure 5) and from the midshaft femur cortex (Figure 4, G-I, and Supplemental Figure 5). Three-point bending tests on femurs taken from these mice revealed that the improved cortical bone properties observed consistently in Sost but not Dkk1 mutants, and to a much greater extent in Dkk1/Sost mutants, translated into improved mechanical properties (Figure 5, A-C, and Supplemental Figure 6). Histomorphometric measurements of fluorochrome-derived bone formation rates from the midshaft femur were consistent with $\mu \mathrm{CT}$ and biomechanics results, and revealed potent anabolic action of Dkk1 deletion when Sost was co-deleted (Figure 5, D and E). To assess changes in the WNT/ $\beta$-catenin pathway under the different genetic conditions, demineralized histological sections from the mice were prepared and stained for active $\beta$-catenin (Supplemental Figure 7). Qualitatively, we found an increase in active $\beta$-catenin signaling in all 3 mutants compared with WT controls, though a particularly strong signal was 


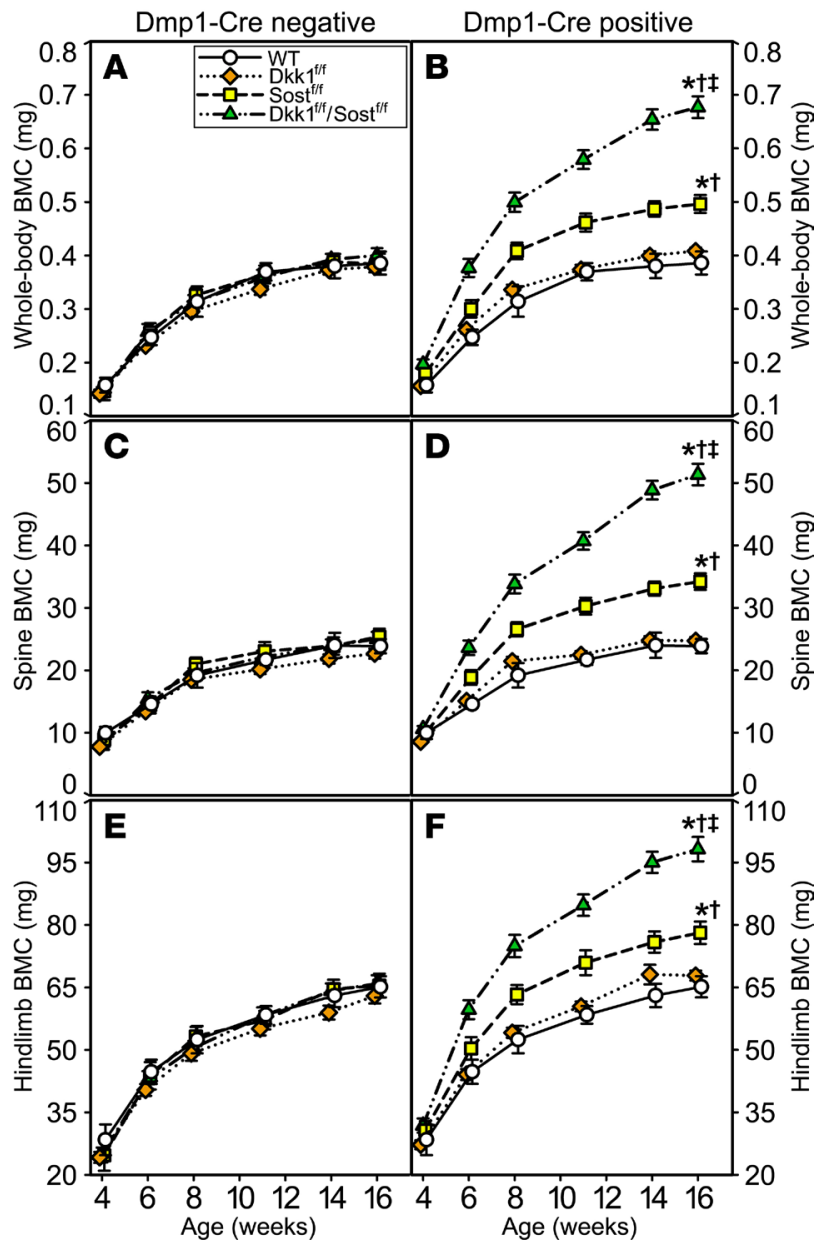

Figure 3. Conditional deletion of Dkk1 from bone consistently increases bone mineral content when Sost is co-deleted in the same bone cell population. Serial in vivo DXA scans of WT $\left(D k k 1^{+/+} S o s t^{+/+}\right)$, Dkk1-flox $\left(D k k 7^{f / f l}\right.$ Sost $\left.t^{+/+}\right)$, Sost-flox $\left(D k k 1^{1^{++}}\right.$Sost $\left.t^{f / f}\right)$, and compound flox $\left(D k k f^{f / f l}\right.$ Sost $\left.t^{f / f}\right)$ mice, collected every 2-3 weeks and analyzed for (A and B) whole-body BMC, (C and D) lumbar spine BMC, and (E and $\mathbf{F}$ ) BMC of the right hindlimb distal to the acetabulum. Data in $\mathbf{A}, \mathbf{C}$, and $\mathbf{E}$ show data from Cre-negative mice only; data in $\mathbf{B}, \mathbf{D}$, and $\mathbf{F}$ show data from Cre-positive mice only. Results in all panels are based on data from female mice; corresponding data from male mice are provided in the supplemental material. ${ }^{*} P<0.05$ compared with WT mice; $\dagger P<0.05$ compared with $D k k f^{f / f l}$ mice; $\ddagger P<0.05$ compared with Sost $t^{f / f l}$ mice. For all curves, $n=6-14$ mice/group. All panels were analyzed using repeated-measures ANOVA followed by Fisher's protected LSD post hoc tests.

observed in the single Dkk1 mutant mice. In summary, Dkk1 deletion from bone cells had little to no effect on skeletal properties, but the same Dkk1 mutations had dramatic osteoanabolic effects when moved onto a bone-selective Sost mutant background. These results suggest that the inability of Dkk1 deletion to consistently and robustly improve skeletal properties is at least partially explained by a compensatory increase in Sost expression.

Dkk1-neutralizing antibody consistently and robustly improves bone mass and strength when administered to Sost ${ }^{-1}$ but not Sost ${ }^{+/+}$mice. Having found that Dkk1 conditional loss-of-function alleles improved bone properties only when moved onto a bone-selective Sost mutant background, we next applied this concept to Dkk1 antibody efficacy, to determine whether we could create a condition where the otherwise inefficacious Dkk1 antibody (e.g., Figure 1, D-F) is significantly anabolic. To address this possibility experimentally, global Sost-knockout (Sost ${ }^{-/}$) and WT (Sost ${ }^{+/+}$) female mice were generated, raised to 8 weeks of age, and administered a Dkk1 antibody treatment regimen $(25 \mathrm{mg} / \mathrm{kg}$ s.c., twice a week for 8 weeks). Dkk1 antibody therapy increased DXA-derived whole-body BMC by $12 \%(P<0.05)$ among WT mice, but the same therapy in Sost ${ }^{-1}$ mice produced a 63\% $(P<0.05)$ increase in BMC (Figure 6A and Supplemental Figure 8). pQCT-derived changes in proximal tibia BMC were not significantly affected by Dkk1 antibody in WT mice, but in Sost $^{-1}$ mice, Dkk1 antibody increased BMC by 32\% $(P<0.05$; Figure 6B and Supplemental Figure 8$)$. $\mu \mathrm{CT}$ properties of the femur after 8 weeks of antibody treatment revealed a small but significant increase in cancellous bone volume fraction at the distal femur among WT mice treated with Dkk1 antibody, compared with WT mice treated with vehicle ( $2 \%$ difference, $P<0.05)$. A much greater difference was observed among Sost ${ }^{-1-}$ mice treated with Dkk1 antibody versus vehicle (47\% increase, $P<0.05$; Figure 6, C and D, and Supplemental Figure 8). No effect of Dkk1 antibody was found among WT mice for midshaft femur and parietal $\mu \mathrm{CT}$ properties, whole femur mechanical properties, or periosteal bone formation rates (Figure 6, E-I, and Supplemental Figure 8), but each of these end points exhibited significant antibody-induced increases when 
A
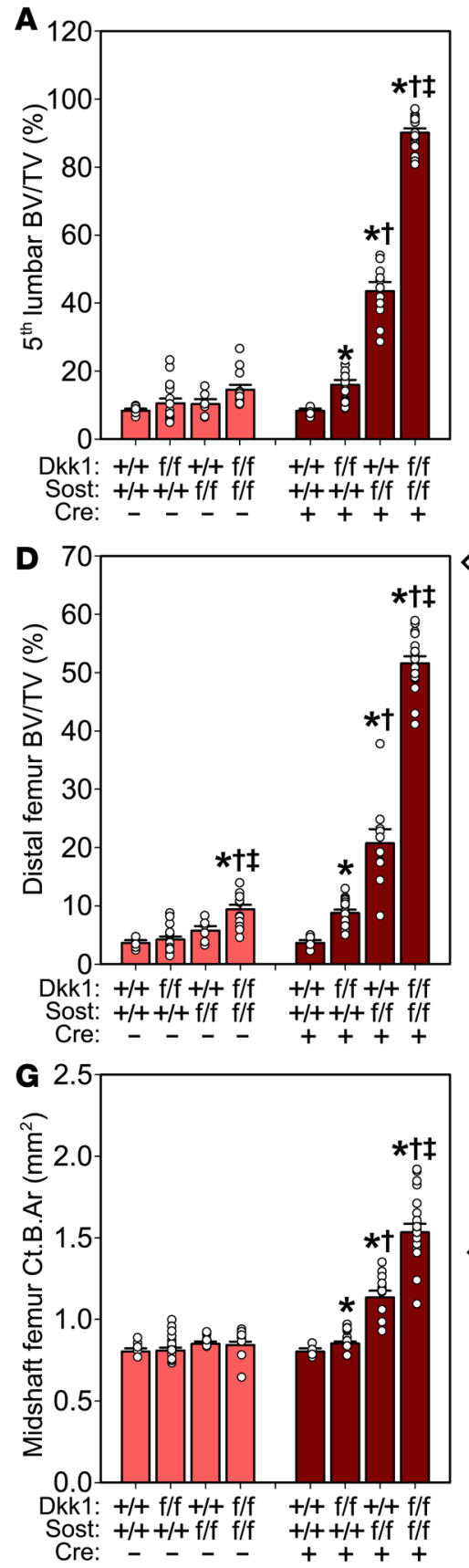

B

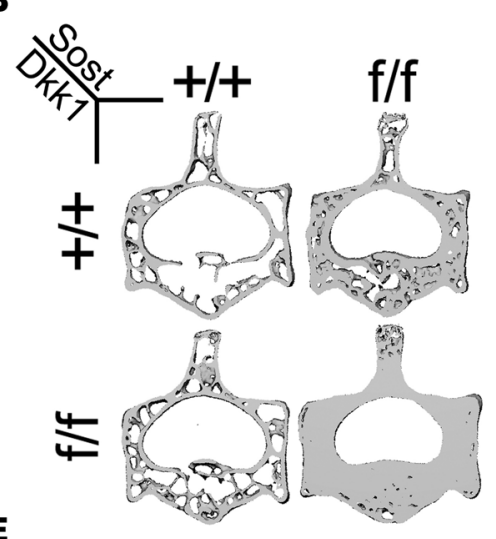

0
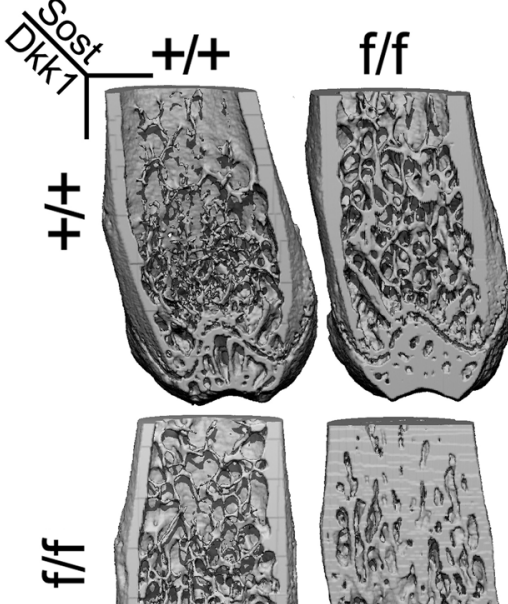

a.

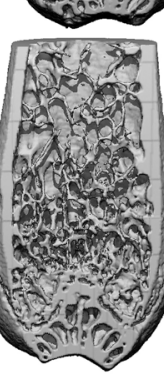

I

ofs

$+/+$

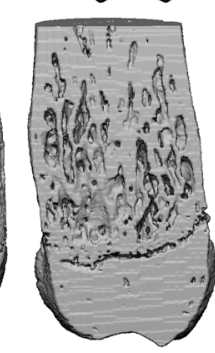

$+$
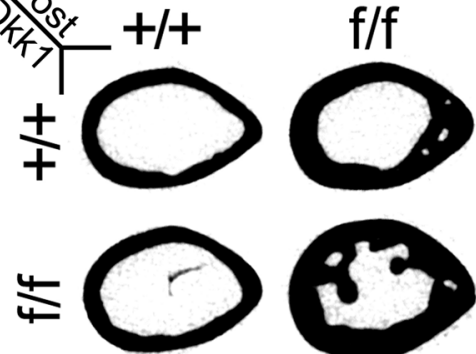

C

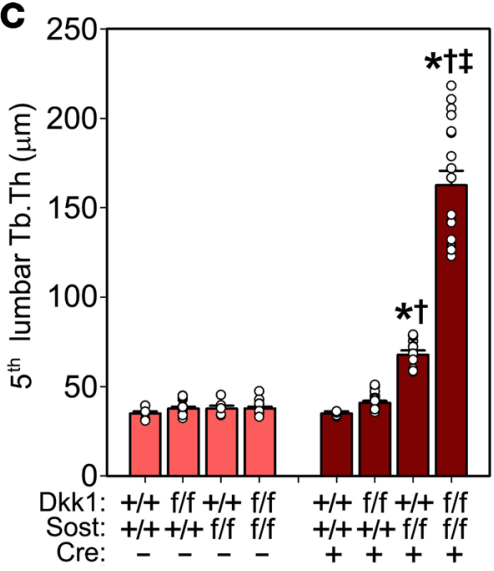

F
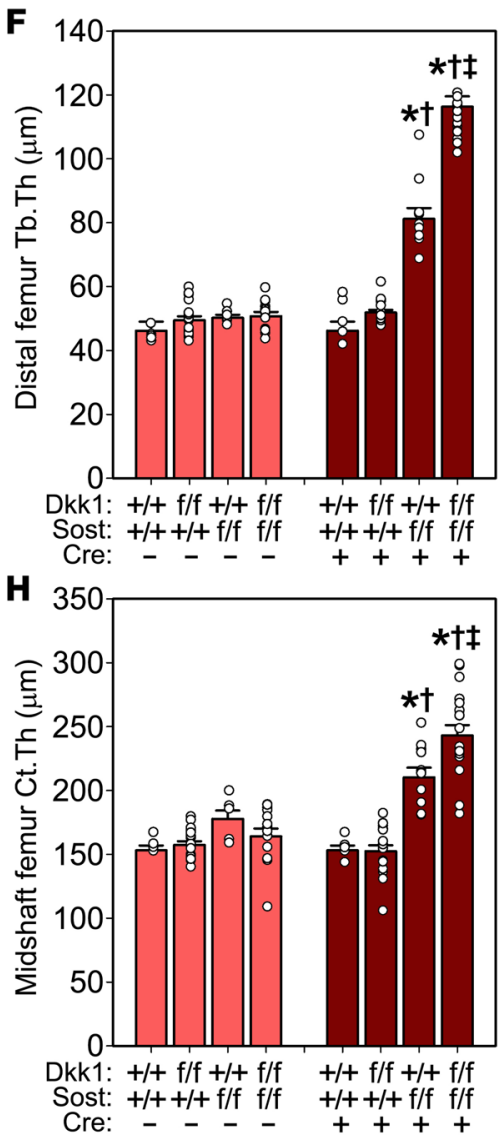

Figure 4. Conditional deletion of Dkk1 from bone improves cancellous and cortical bone architecture dramatically when Sost is co-deleted in the same bone cell population. $\mu C T$-derived measurement of $L_{5}$ vertebral body cancellous bone, distal femur metaphyseal cancellous bone, and

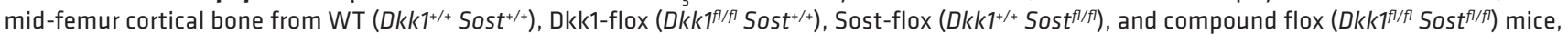
with (maroon bars) and without (red bars) the ${ }^{10 \mathrm{~kb}} \mathrm{Dmp} 1-$ Cre transgene. Quantitative differences in $\mathrm{L}_{5}$ trabecular bone volume fraction (BV/TV; A) and thickness (Tb.Th; C) can be appreciated from representative 3D tomographic reconstructions (C) of the central 30\% of the vertebra from Cre-positive mice. Quantitative differences in distal femur trabecular (D) bone volume fraction and (F) thickness can be appreciated from (E) representative $3 D$ reconstructions of the caudal half of the distal femur (the ventral half was digitally removed) in Cre-positive mice. Quantitative differences in midshaft femur cortical bone area (Ct.B.Ar; G) and thickness (Ct.Th; H) can be appreciated from (I) representative $2 \mathrm{D}$ slices taken from the femur mid-diaphysis of Cre-positive mice. Results in all panels are based on data/images from female mice; corresponding data/images from male mice are provided in the supplemental material. ${ }^{*} P<0.05$ compared with Cre-matched WT mice; †P<0.05 compared with Cre-matched $D k k 1^{f l / f 1}$ mice; $¥ P$ $<0.05$ compared with Cre-matched Sost ${ }^{f / f l}$ mice. For all panels, $n=6-14$ mice/group. All data panels were analyzed using 1-way ANOVA followed by Fisher's protected LSD post hoc tests. 

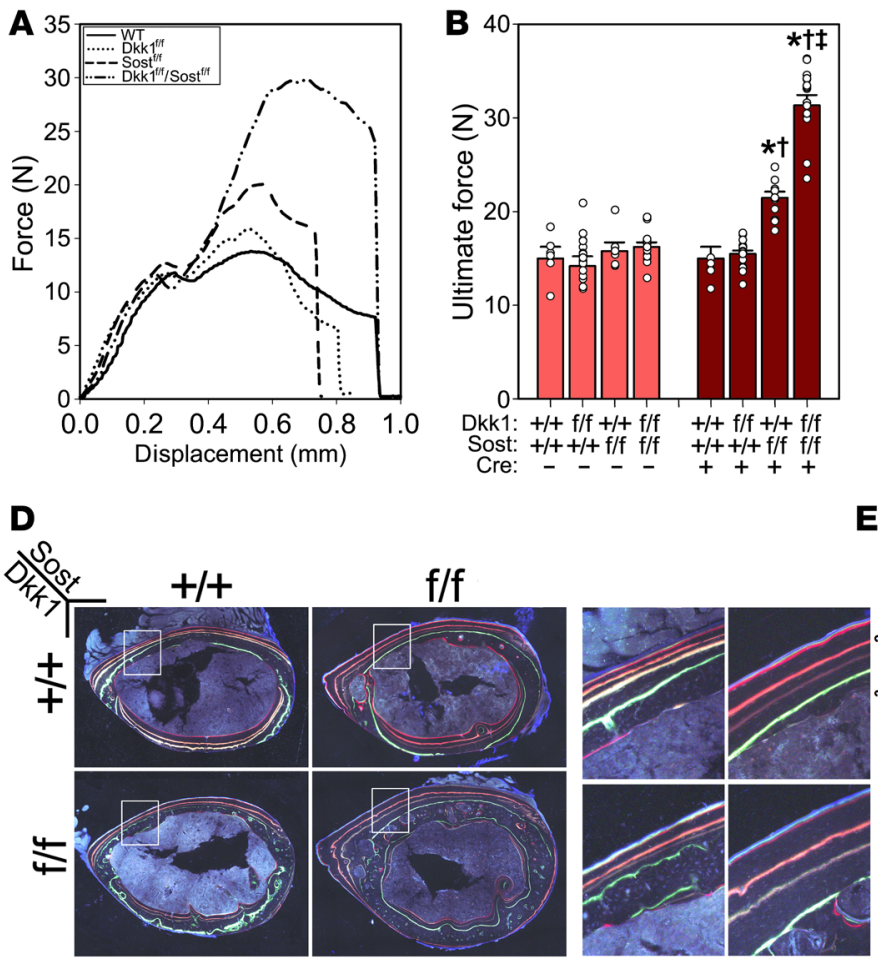
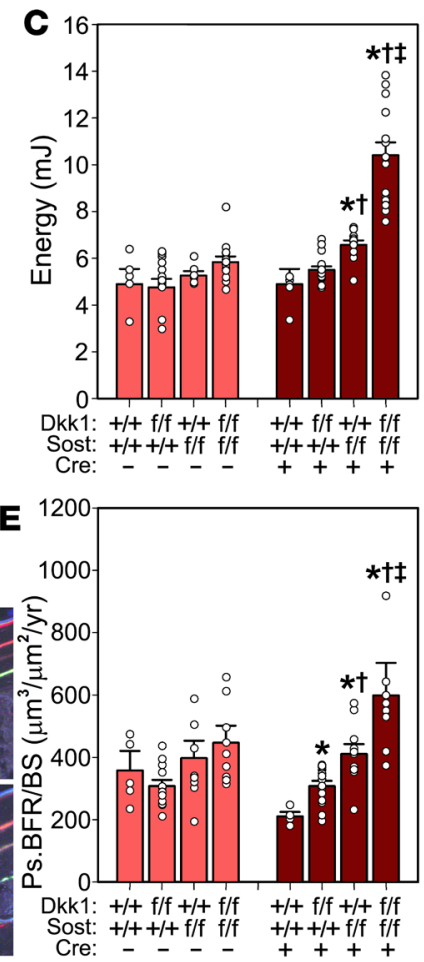

Figure 5. Conditional deletion of Dkk1 from bone improves mechanical properties and increases anabolic action significantly when Sost is co-deleted in the same bone cell population. (A-C) Three-point monotonic bending tests to failure conducted on whole femurs from WT $\left(D k k 1^{+/+}\right.$Sost $\left.{ }^{+/+}\right)$, Dkk1flox $\left(D k k 1^{f / f l} S o s t^{+/+}\right)$, Sost-flox $\left(D k k 1^{+/+}\right.$Sost $\left.t^{f / f}\right)$, and compound flox (Dkk $7^{f / / f l}$ Sost $\left.t^{f / f}\right)$ mice, with (maroon bars) and without (red bars) the ${ }^{10 k b} D m p 1-C r e$ transgene. (A) Representative force-displacement curves from tests conducted on Cre-positive mice reveal differences in mechanical properties among genotypes; quantification of (B) ultimate force (peak height of the curve) and (C) energy absorbed (area under the curve). (D) Midshaft femur histologic sections from fluorochrome-labeled Cre-positive mice, calculated from 4 to 14 weeks, reveal differences in bone formation rates, which can be appreciated by noting the distance between each of the 4 unique labels injected intermittently during the experimental period (calcein [green] at 4 weeks; oxytetracycline [yellow] at 6 weeks; demeclocycline [orange] at 8 weeks; alizarin [red] at 14 weeks). Panels on the right are magnifications of the indicated regions in the left panels. Width of white inset boxes, $350 \mu \mathrm{m}$. (E) Quantification of anabolic action on the periosteal surface (Ps), calculated as the bone formation rate per unit bone surface (BFR/BS). Results in all panels are based on data/images from female mice; corresponding data/images from male mice are provided in the supplemental material. For $\mathbf{A}-\mathbf{C}, n=6-14$ mice/group. For $\mathbf{E}, n=6-9$ mice/group. ${ }^{*} P<0.05$ compared with Cre-matched WT mice; ${ }^{\dagger} P<0.05$ compared with Cre-matched $D k k^{7 / / f l}$ mice; ${ }^{\ddagger} P<0.05$ compared with Cre-matched Sost $t^{f / f l}$ mice. Data in $\mathbf{B}, \mathbf{C}$, and $\mathbf{E}$ were analyzed using 1-way ANOVA within each Cre grouping, followed by Fisher's protected LSD post hoc tests.

tested in Sost ${ }^{-1-}$ mice. In summary, Dkk1 antibody is highly effective at increasing bone mass and anabolic action in the skeleton when sclerostin upregulation is prevented; failure to suppress sclerostin upregulation renders Dkk1 antibody therapy ineffective.

Co-administration of antibodies against sclerostin and Dkk1 to WT mice generates a synergistic effect on bone properties that far exceeds additive effects. Our results to this point indicated that Dkk1 antibody is highly osteoanabolic if Sost upregulation is prevented at the genomic level. To take those findings into a more translational setting, we investigated the potential of pharmacologically inhibiting sclerostin action using neutralizing antibody to sclerostin (Sclr-mAb) during Dkk1 antibody administration. For these experiments, we used 8-week-old female WT C57BL/6 (B6) mice and treated them with sclerostin antibody, Dkk1 antibody, or both (simultaneously), each at $25 \mathrm{mg} / \mathrm{kg}$ s.c., twice a week for 8 weeks. Consistent with our previous experiments, Dkk1$\mathrm{mAb}$ treatment alone resulted in little to no improvement in bone properties (Figure 7, A-G, and Supplemental Figure 9), but Dkk1-mAb administration in the presence of Sclr-mAb (combination treatment) improved whole-body BMC by 43\% compared with Sclr-mAb alone (Figure 7A); improved distal femur bone volume fraction and trabecular thickness by $26 \%$ and $74 \%$, respectively (Figure 7, B-D); and improved femoral cortical thickness and ultimate force by $7 \%$ and $11 \%$, respectively (Figure 7, E and F). The improvements in bone properties generated by combination therapy were driven by both increased anabolic action (Figure 7G) and a reduction in resorption (Supplemental Figure 9). No obvious side effects of single or dual antibody treatments were observed (e.g., body weight or behavioral changes). In summary, Dkk1 antibody is potently anabolic 
A
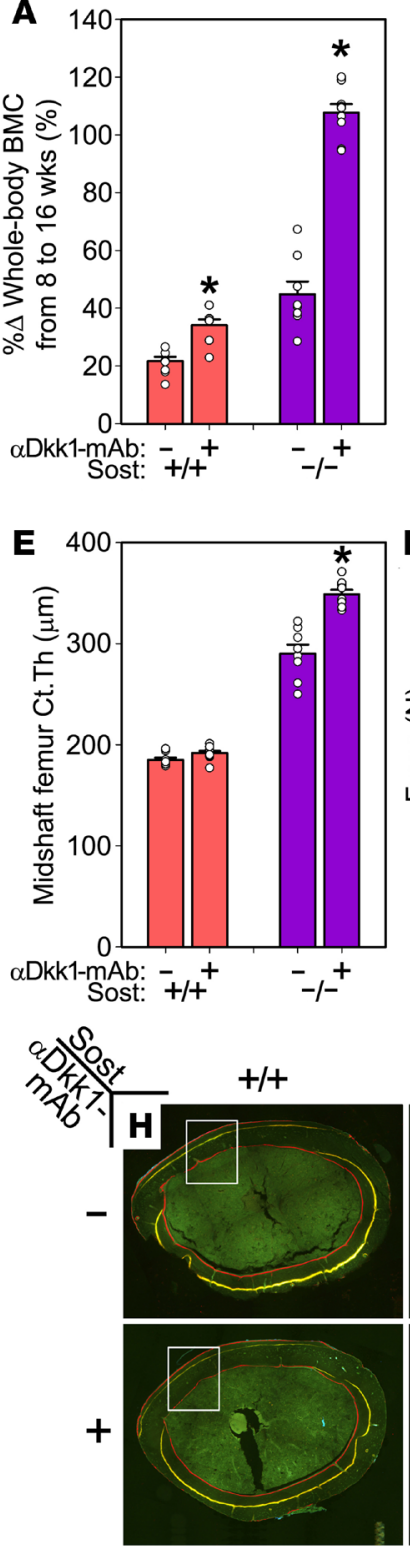
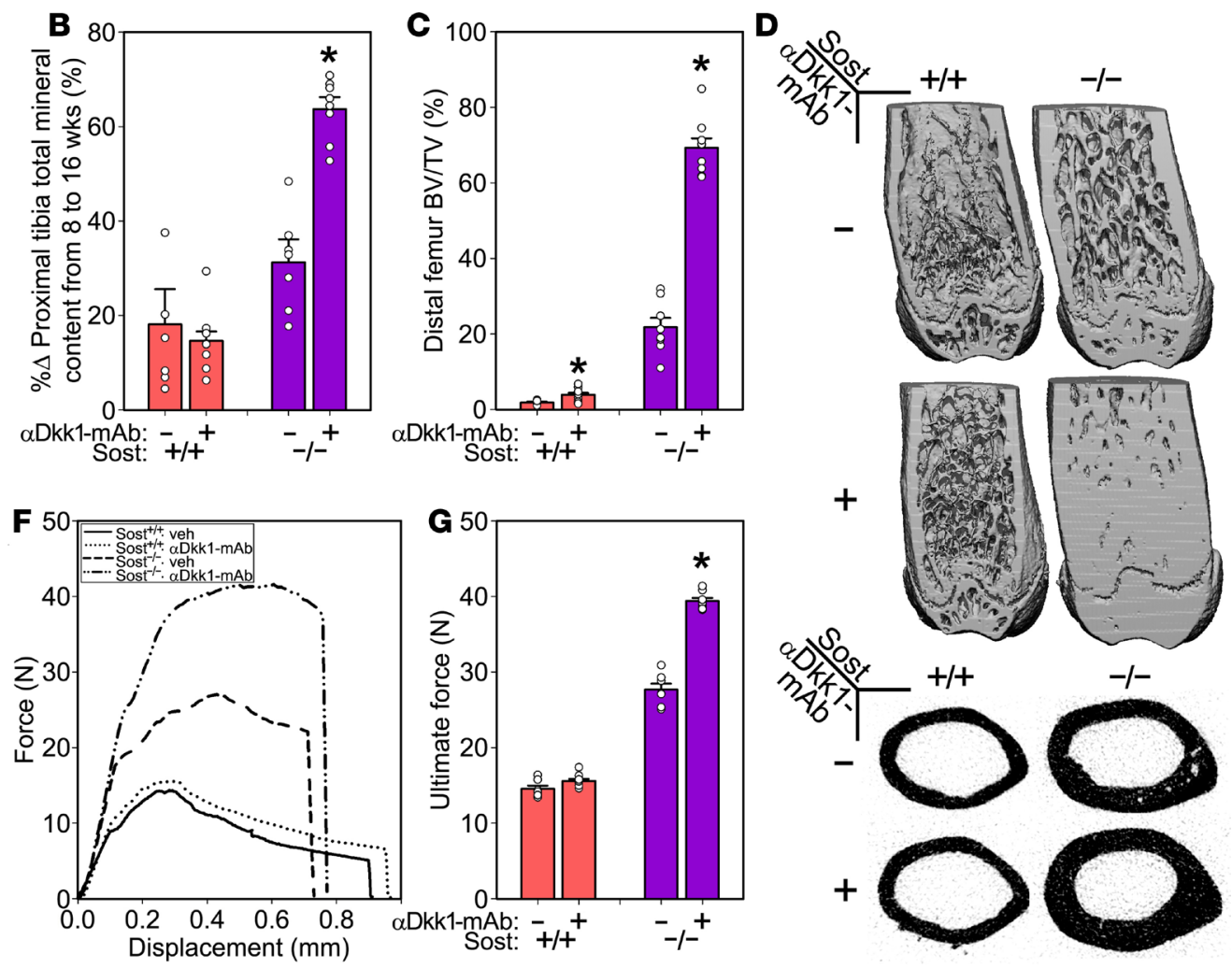

I
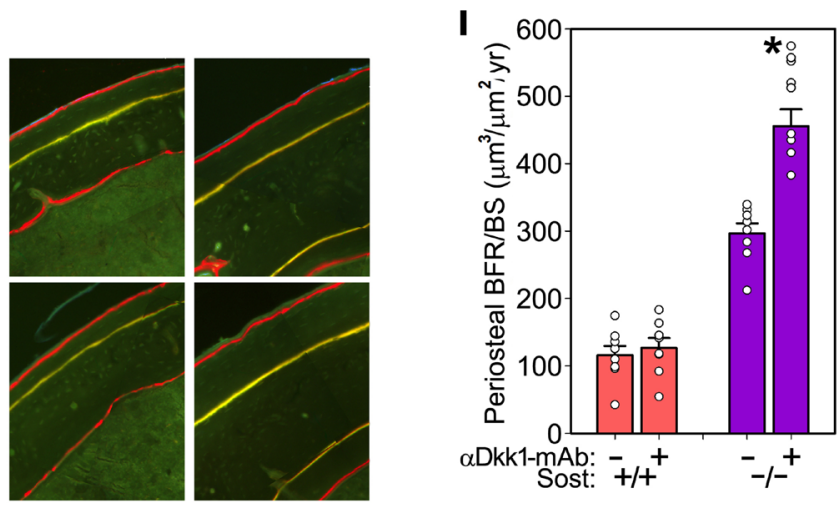

Figure 6. Dkk1 neutralizing antibody has negligible skeletal effects in WT mice but has potent anabolic effects in Sost ${ }^{-/-}$mice. Percent change in (A) whole-body bone mineral content (BMC) and (B) proximal tibia BMC, calculated from just prior to the start of treatment (at 8 weeks of age) to sacrifice at 16 weeks of age, capturing 8 weeks of Dkk1 mAb ( $\alpha$ Dkk1-mAb) or vehicle injection in WT (red bars) and Sost ${ }^{-/-}$(purple bars) mice. (C-E) Femoral $\mu$ CT properties in the distal metaphyseal spongiosa (bone volume fraction [BV/TV]) and midshaft cortex (cortical thickness [Ct.Th]) measured in 16-weekold mice, after 8 weeks of vehicle or Dkk1 antibody treatment. Note the increase in bone mass induced by Dkk1 inhibition in Sost ${ }^{-/-}$but not WT mice. (G-I) Quantification of (G) ultimate force from 3-point bending tests of the femoral diaphysis and (I) bone formation rates from the same region, revealing increased bone strength and formation rates induced by Dkk1 inhibition in Sost ${ }^{-/-}$but not WT mice. Representative fluorochrome-labeled sections $(\mathbf{H})$ illustrate the increase in bone formation over the experimental period (from yellow to red label). All panels are based on data/images from female mice. ${ }^{*} P<0.05$ compared with genotype-matched vehicle-treated mice. For all experiments, $n=9-12$ mice/group. Data in A, B, C, E, G, and I were analyzed using unpaired $t$ tests within each Sost background.

when sclerostin protein function is disabled by neutralizing antibody, supporting our previous observations that the skeletal efficacy of Dkk1 inhibition can be unlocked if the compensatory effects of sclerostin upregulation are countered.

\section{Discussion}

Our main objective in the current communication was to understand why neutralization of Dkk1 - a potent LRP5/6 antagonist — fails to generate a robust osteoanabolic response. We found that Dkk1 inhibition via 

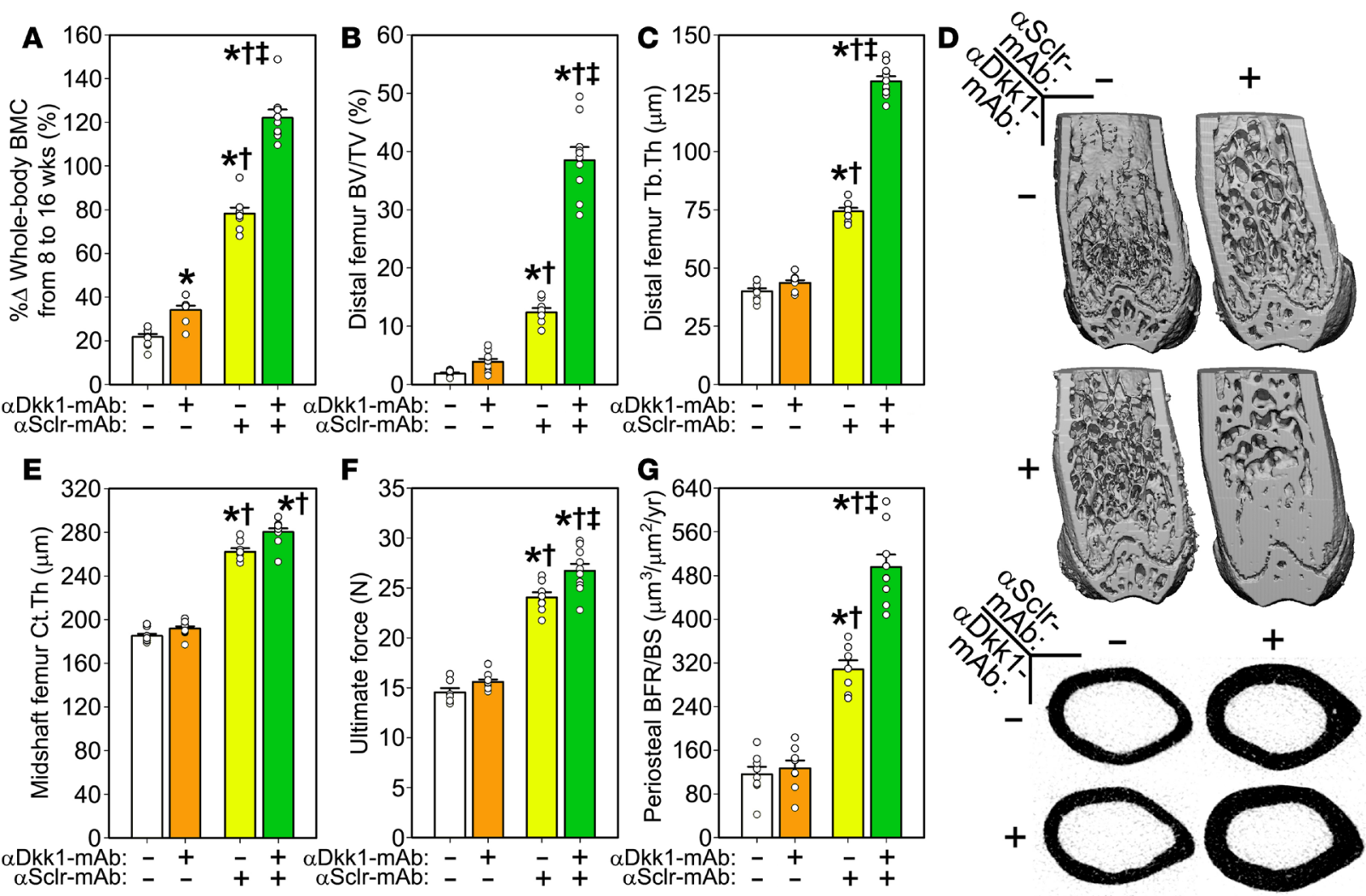

Figure 7. Dkk1-neutralizing antibody has potent osteoanabolic effects in WT mice when sclerostin is pharmacologically inhibited. (A) Percent change in whole-body bone mineral content (BMC) calculated from just prior to the start of treatment (at 8 weeks of age) to sacrifice at 16 weeks of age, capturing 8 weeks of Dkk1 mAb ( $\alpha$ Dkk1-mAb; orange bars), sclerostin mAb ( $\alpha$ Sclr-mAb; yellow bars), co-injection with both antibodies (green bars), or vehicle (white bars) in female WT mice. Femoral $\mu \mathrm{CT}$ properties (B-E), biomechanical properties $(\mathbf{F})$ and bone formation rates $(\mathbf{G})$ were quantified for all treatment groups as described above. ${ }^{*} P<0.05$ compared with vehicle-treated mice; $\uparrow P<0.05$ compared with $\alpha$ Dkk1-mAb-treated mice; $\ddagger P<0.05$ compared with $\alpha$ SclrmAb-treated mice. For all panels, $n=10-12$ mice/group. Data in all panels were analyzed using 1-way ANOVA, followed by Fisher's protected LSD post hoc tests. BV/TV, trabecular bone volume fraction; Ct.Th, cortical thickness; Tb.Th, and thickness; BFR/BS, bone formation rate per unit bone surface.

either selective genetic deletion in osteocytes, or antibody-based neutralization, resulted in increased Sost expression, as revealed by in vivo Sost reporter activity and quantitative PCR. To determine whether the increase in Sost was responsible for impaired anabolic action of Dkk1 neutralization, we deleted Sost in osteocytes, deleted Sost globally, or neutralized sclerostin with antibody; in all 3 contexts, Dkk1 genetic deletion from bone or pharmacologic Dkk1 inhibition was significantly and potently anabolic. In other words, the skeletal effects of Dkk1 inhibition are strong but are only manifest when Sost/sclerostin is disabled. Those observations suggest that the increase in Sost/sclerostin that occurs under Dkk1-disabiling conditions acts to restrain the otherwise potently anabolic action of Dkk1 inhibition. These data, in conjunction with those from other groups showing the reciprocal phenomenon (i.e., that Dkk1 expression is increased under Sost/sclerostin-disabling conditions [refs. 32-34]), indicate that sclerostin and Dkk1 might exhibit mutual compensatory regulation, where one molecule can become more highly expressed when the other is selectively suppressed. Given that outcome, a larger question emerges: why does sclerostin neutralization result in such abundant increases in bone mass, despite the concurrent upregulation of Dkk1, yet Dkk1 neutralization is largely ineffective because of the concurrent upregulation of Sost?

One potential explanation for differences in sclerostin- versus Dkk1-mediated inhibition of osteoanabolism might be related to selectivity of local facilitator proteins. Recent work on the role of LRP4 in bone indicates that the receptor serves as a facilitator of sclerostin but not Dkk1 action on WNT1/ $\beta$-catenin signaling (44). Although both sclerostin and Dkk1 interact with LRP4 $(44,45)$, neither overexpression nor knockdown of LRP4 impacts Dkk1's ability to impair WNT signaling in bone cells. Further, mice that express HBM-causing mutations in LRP5 (e.g., A214V or G171V) exhibit protection from bone-driven sclerostin overexpression but not Dkk1 overexpression $(46,47)$. Thus, while the biology of sclerostin- and 
Dkk1-mediated effects on bone mass are not well understood, it is clear that these two molecules engage different mechanisms to affect WNT signaling and bone mass.

Previous genetic models of Dkk1 loss of function have relied on global heterozygous inactivation of the gene (+/-) or on naturally occurring global hypomorphic alleles (e.g., doubleridge) to assess skeletal consequences of Dkk1 genetic impairment (29). Our experiments are the first to our knowledge to selectively target Dkk1 in bone tissue, using mice with homozygous Dkk1 floxed alleles that were recombined using the ${ }^{10 \mathrm{~kb}} \mathrm{D}$ mp1-Cre transgene. Those mice have a very mild skeletal phenotype, as most skeletal end points collected indicate either no difference from Cre-negative mice or, if differences were detected, the effect size was small. One potential explanation for the meager effect on phenotype could be the choice of Cre driver. Dkk1 expression has been detected in tissues other than bone (e.g., skin, bladder, prostate), so our approach which selectively inactivated Dkk1 in Dmp1-expressing cells could have "missed" a more relevant cell type capable of producing a stronger phenotype (e.g., early osteoblasts). However, three observations are noteworthy regarding our choice to use Dmp1-Cre for these experiments: (i) a body-wide screen of Dkk1 expression in young adult mice found that Dkk1 expression was restricted largely to bone (i.e., osteocytes), where very strong expression was detected (48); (ii) both fluorescence-activated cell sorting (49) and laser capture microdissection (50) approaches revealed that Dkk1 is highly upregulated in the osteocyte compared with the osteoblast; and (iii) our data indicate that Dkk1 deletion from Dmp1-expressing cells is highly anabolic if Sost is inhibited, suggesting that inhibiting Dkk1 in this cell type can generate major effects if the right conditions (e.g., Sost inhibition) are achieved. If the osteoanabolic Dkk1 inhibition alone were demonstrable, the mouse would likely be the most robust model to detect the effect given that mice have 10-20 times more circulating Dkk1, and 2-5 times less circulating sclerostin, than rats, cynomolgus monkeys, or humans (Monica Florio, Amgen Inc., personal communication).

It has also been noted that Dkk1 expression is more abundant in bone from young mice, and decreases dramatically in adolescent and adult mice, which might explain why Dkk1 antibody is more efficacious in young versus old mice (i.e., there is more target available to inhibit). However, mice in our Dmp1-Cre $\times$ $D k k 1^{f l f l}$ experiments had Dkk1 deleted from bone since conception, and therefore effects should be manifest in young mice, when Dkk1 is more highly expressed and potentially more active. Moreover, inspection of DXA data at 4 weeks of age and beyond into adulthood (effects during growth should be cumulative) revealed no changes in BMC. Another potential explanation for differences in sclerostin- versus Dkk1-mediated inhibition might be related to selectivity of facilitator proteins. Recent work on the role of LRP4 in bone indicates that the receptor serves as a facilitator of sclerostin but not Dkk1 action on LRP5/6.

Despite its modest effect on bone gain in unperturbed, intact mice, Dkk1 antibody has proven efficacious in certain pathological contexts, such as fracture healing $(30,51)$, multiple myeloma $(52,53)$, and inflammatory arthritis $(54,55)$. Our data suggest that Dkk1 inhibition is highly anabolic in a healthy, intact adult mouse, if the compensatory mechanisms are disabled. The Amgen group approached the Dkk1-sclerostin compensatory regulation phenomenon from a different angle, by looking to make anti-sclerostin antibody more efficacious (33). They reported that Dkk1 levels were increased in sclerostin antibody-treated mice, which they surmised might be restraining a fuller anabolic potential of sclerostin inhibition. That observation prompted them to develop a bispecific antibody that targets both sclerostin and Dkk1, which shows synergistic osteoanabolic action similar to what they (33) and we report for the combined use of individual antibodies to sclerostin and Dkk1. Importantly, the two studies are consistent in finding a synergistic effect of compound sclerostin/Dkk1 inhibition that far exceeds any potential additive effects. The molecular mechanisms that control transcriptional compensation/ upregulation between Sost and Dkk1 are unknown. Sost transcription is regulated by a number of pathways and factors, including Osx (56), Bmps (57), Tgf- $\beta$ (58), histone deacetylases (HDACs) (59), cAMP/PKA (60), and hypoxia (61), among others (reviewed in ref. 62). Dkk1 transcription is regulated by some of these same mechanisms $(63,64)$, but the mechanisms that confer reciprocal maintenance of WNT inhibition remain to be elucidated.

In summary, the osteoanabolic effects of Dkk1 inhibition can be unleashed when sclerostin upregulation is prevented. The role of other secreted inhibitors in the compensatory expression mechanism are unknown. Canonical WNT signaling antagonists such as WISE (65), sFRP4 (66), and NOTUM (67), are associated with skeletal phenotypes in mice when mutated either globally or selectively in bone cells, and sclerostin inhibition enhances a number of these transcripts in mouse bone (68). Whether pharmacologic modulation of these or other members of the secreted WNT inhibitory milieu can improve or otherwise tailor the efficacy of sclerostin and/or Dkk1 neutralizing therapy is not known. 


\section{Methods}

Mice. Development of the conditional Dkk1-flox mouse model has been reported elsewhere (69). Briefly, these mice harbor head-to-toe loxP sequences flanking exons 1 and 2 of the endogenous Dkk1 gene. Development of the conditional Sost-flox mouse model has been reported elsewhere (43). Briefly, these mice harbor a COIN module in the single Sost intron, flanked by mutant loxP sequences introduced in a head-to-head arrangement. Development of the Sost-LacZ knockin reporter/null mouse model has been reported elsewhere (43). Briefly, these mice harbor a LacZ-neo cassette in place of the endogenous Sost coding sequence. Development of the ${ }^{10 \mathrm{~kb}} \mathrm{Dmp} 1-\mathrm{Cre}$ transgenic mouse model has been reported elsewhere (70). Briefly, these mice harbor a transgene expressing Cre recombinase, driven by a 9.6-kb fragment of the mouse dentin matrix protein 1 (Dmp1) promoter. Development of the ${ }^{2.3 \mathrm{~kb}}$ Colla1-Dkk1 transgenic mouse model has been reported elsewhere (48). Briefly, these mice harbor a transgene expressing a mouse Dkk1 cDNA, driven by a 3.2-kb fragment of the rat collagen 1A1 promoter. All mouse colonies were on a mixed background of B6 and 129/SvJ, ranging from $93.8 \%$ to $100 \%$ B6, depending on the colony. For all experiments, littermate controls were used to stabilize the effect of genetic background within experiments.

Antibodies. Details of the development of Dkk1- and sclerostin-neutralizing antibodies have been reported elsewhere $(16,54)$. Briefly, the $\mathrm{Dkk} 1$ antibody is a neutralizing rat $\mathrm{mAb}$ raised against mouse Dkk1, and the sclerostin antibody, which neutralizes mouse sclerostin, is a version of a mouse mAb in which the amino acid sequence has been modified for use in rats. Antibodies were injected into mice s.c. at $25 \mathrm{mg} / \mathrm{kg}$, twice per week. Vehicle treatment was the buffer in which the antibodies were made. Treatment duration is indicated in the figure legend for each experiment.

$D X A$. Collection of serial DXA measurements on live mice are described and validated elsewhere (13). Briefly, isoflurane-anesthetized mice were scanned periodically on a PIXImus II (GE Lunar). BMC was measured from the scans for the whole body, lumbar spine $\left(\mathrm{L}_{3}-\mathrm{L}_{5}\right)$, and right lower limb.

$\mu C T$. Formalin-fixed femurs, $\mathrm{L}_{5}$ vertebrae, and craniums were scanned, reconstructed, and analyzed as previously described $(13,71,72)$ using either $13-\mu \mathrm{m}$ resolution, $50-\mathrm{kV}$ peak tube potential and $151-$ $\mathrm{ms}$ integration time (femur and vertebra) or $20-\mu \mathrm{m}$ resolution, $50-\mathrm{kV}$ peak tube potential and $125-\mathrm{ms}$ integration time (cranium). Standard parameters (73) related to cancellous and cortical bone architecture were measured.

$p Q C T$. Collection of serial tibial pQCT measurements in live mice is described elsewhere (74). Briefly, a single slice through the proximal tibia and one through the midshaft tibia were collected on isoflurane-anesthetized mice using a Stratec x-ray microscope (Stratec Inc.) at $70-\mu \mathrm{m}$ resolution. Slices were analyzed for BMC using Stratec software in peel mode 2.

Histology. Mice were given various combinations of oxytetracycline $\mathrm{HCl}(80 \mathrm{mg} / \mathrm{kg}$, s.c.), calcein (12 $\mathrm{mg} / \mathrm{kg}$, i.p.), alizarin complexone (20 mg/ kg, i.p.), and demeclocycline (40 mg/ $\mathrm{kg}$, i.p.) to label mineralizing bone, at the time points indicated for each experiment (see figure legends). After sacrifice, femurs were processed, and cut, for plastic-embedded histomorphometry as previously described (72). Briefly, the periosteal bone formation parameters mineralizing surface (MS/BS; \%), mineral apposition rate (MAR; $\mu \mathrm{m} / \mathrm{d}$ ), and bone formation rate (BFR/BS; $\mu \mathrm{m}^{3} / \mu \mathrm{m}^{2} / \mathrm{yr}$ ), were calculated using standard protocols (75). Frozen sections of unfixed Sost-LacZ reporter mouse thighs were cut and reacted for $\beta$-galactosidase activity as previously described (65). Demineralized paraffin-embedded longitudinal thin sections cut through the proximal tibia were immunolabeled for active $\beta$-catenin and counterstained for DAPI as previously described (65).

Mechanical properties. Parameters related to whole bone strength were measured using 3-point bending tests as previously described (41). Briefly, each femur was loaded to failure in monotonic compression, during which force and displacement were collected every 0.01 seconds. From the force/displacement curves, ultimate force and energy to failure were calculated using standard equations (76).

Serum C-terminal telopeptide (CtX). Serum concentration of the resorption marker CtX was measured by a commercially available ELISA (RatLaps; IDS Inc.) as previously described (13, 72). Briefly, blood samples were collected from the retromandibular vein, permitted to clot at room temperature for 30 minutes, spun at 5,000 $\mathrm{g}$ to separate the serum, and frozen at $-80^{\circ}$. Thawed serum samples were assayed for $\mathrm{CtX}$ in triplicate according to the manufacturer's instructions.

Gene expression via quantitative PCR. Snap-frozen femur and tibia diaphyses were pulverized in liquid $\mathrm{N}_{2}$ and processed for total RNA isolation as previously described (77). Briefly, total RNA was reversed transcribed into cDNA using random hexamers; measured; then reacted for Sost, Dkk1, and the housekeeping 
gene Hprt1 using quantitative PCR-based Taqman Assay-on-Demand kits. The $\Delta \triangle \mathrm{CT}$ method was used to calculate relative expression, which was normalized for each sample using Hprt1.

Bone matrix properties. Humerus midshaft samples were processed and measured for bone matrix composition as previously described (78). Briefly, fixed bone samples were embedded in resin, cut, mounted to plastic slides, polished, and measured using FTIRI at the National Synchrotron Light Source at the Brookhaven National Laboratory (U10B beamline). A total of 64 scans were collected and averaged for each spectra, which were subsequently processed using previously published spectral analysis methods (79).

Statistics. Statistical analyses were computed with JMP (version 4.0, SAS Institute Inc.). The radiographic, histomorphometric, and biomechanical endpoints were analyzed using 1- or 2-way ANOVA, with genotype and/or antibody treatment as main effects. Time series data were analyzed with repeated-measures ANOVA. When at least one main effect was significant, interactions terms were calculated and tested for significance. Differences among groups were tested for significance with Fisher's protected least significant difference (LSD) post hoc test. Statistical significance was taken at $P<0.05$. Two-tailed distributions were used for all analyses. Data are presented as mean \pm SEM.

Study approval. All mouse procedures were performed in accordance with the IACUC guidelines and approvals.

\section{Author contributions}

PCW, WAB, and ALA conducted the genetic experiments involving compound flox mice. SER and AGR conducted the antibody studies in Sost ${ }^{--}$and WT mice. DJH and KEL conducted the $\mu \mathrm{CT}$ analysis and histomorphometry work. KSK performed the LacZ studies and biomechanical testing. RDR conducted the FTIRI measurements at the Brookhaven National Laboratory. GGL contributed intellectual input. AGR designed the experiments and wrote the manuscript.

\section{Acknowledgments}

Financial support was provided by the NIH (AR053237 to AGR; DK075730 to GGL; AR070624 to WAB), the US Department of Veterans Affairs (BX001478 to AGR) the US Department of Energy (DE-AC5207NA27344 to GGL). Sclerostin and Dkk1 antibodies were provided by Amgen Inc. and UCB (Brussels, Belgium). Monica Florio provided comparative data on serum sclerostin and Dkk1 levels in humans, monkeys, rats, and mice. The content is solely the responsibility of the authors and does not necessarily represent the official views of the NIH. The funders had no role in study design, data collection and analysis, decision to publish, or preparation of the manuscript.

Address correspondence to: Alexander G. Robling, Department of Anatomy \& Cell Biology, Indiana University School of Medicine, 635 Barnhill Drive, MS 5035, Indianapolis, Indiana 46202, USA. Phone: 317.274.7489; Email: arobling@iupui.edu.

1. Gong Y, et al. LDL receptor-related protein 5 (LRP5) affects bone accrual and eye development. Cell. 2001;107(4):513-523.

2. Biha N, Ghaber SM, Hacen MM, Collet C. Osteoporosis-pseudoglioma in a Mauritanian child due to a novel mutation in LRP5. Case Rep Genet. 2016;2016:9814928.

3. Tüysüz B, Bursalı A, Alp Z, Suyugül N, Laine CM, Mäkitie O. Osteoporosis-pseudoglioma syndrome: three novel mutations in the LRP5 gene and response to bisphosphonate treatment. Horm Res Paediatr. 2012;77(2):115-120.

4. Costantini A, Kekäläinen P, Mäkitie RE, Mäkitie O. High bone mass due to novel LRP5 and AMER1 mutations. Eur J Med Genet. 2017;60(12):675-679.

5. Van Wesenbeeck L, et al. Six novel missense mutations in the LDL receptor-related protein 5 (LRP5) gene in different conditions with an increased bone density. Am J Hum Genet. 2003;72(3):763-771.

6. Rickels MR, Zhang X, Mumm S, Whyte MP. Oropharyngeal skeletal disease accompanying high bone mass and novel LRP5 mutation. J Bone Miner Res. 2005;20(5):878-885.

7. Little RD, et al. A mutation in the LDL receptor-related protein 5 gene results in the autosomal dominant high-bone-mass trait. Am J Hum Genet. 2002;70(1):11-19.

8. Ettenberg SA, et al. Inhibition of tumorigenesis driven by different Wnt proteins requires blockade of distinct ligand-binding regions by LRP6 antibodies. Proc Natl Acad Sci USA. 2010;107(35):15473-15478.

9. Li X, et al. Targeted deletion of the sclerostin gene in mice results in increased bone formation and bone strength. $J$ Bone Miner Res. 2008;23(6):860-869.

10. Lin C, et al. Sclerostin mediates bone response to mechanical unloading through antagonizing Wnt/beta-catenin signaling. $J$ Bone Miner Res. 2009;24(10):1651-1661.

11. Winkler DG, et al. Osteocyte control of bone formation via sclerostin, a novel BMP antagonist. EMBO J. 2003;22(23):6267-6276. 
12. Kramer I, Loots GG, Studer A, Keller H, Kneissel M. Parathyroid hormone (PTH)-induced bone gain is blunted in SOST overexpressing and deficient mice. J Bone Miner Res. 2010;25(2):178-189.

13. Kedlaya R, et al. Sclerostin inhibition reverses skeletal fragility in an Lrp5-deficient mouse model of OPPG syndrome. Sci Transl Med. 2013;5(211):211ra158.

14. Marenzana M, et al. Sclerostin antibody treatment enhances bone strength but does not prevent growth retardation in young mice treated with dexamethasone. Arthritis Rheum. 2011;63(8):2385-2395.

15. Jacobsen CM, et al. Targeting the LRP5 pathway improves bone properties in a mouse model of osteogenesis imperfecta. $J$ Bone Miner Res. 2014;29(10):2297-2306.

16. Li X, et al. Sclerostin antibody treatment increases bone formation, bone mass, and bone strength in a rat model of postmenopausal osteoporosis. J Bone Miner Res. 2009;24(4):578-588.

17. Tian X, Jee WS, Li X, Paszty C, Ke HZ. Sclerostin antibody increases bone mass by stimulating bone formation and inhibiting bone resorption in a hindlimb-immobilization rat model. Bone. 2011;48(2):197-201.

18. Tian X, Setterberg RB, Li X, Paszty C, Ke HZ, Jee WS. Treatment with a sclerostin antibody increases cancellous bone formation and bone mass regardless of marrow composition in adult female rats. Bone. 2010;47(3):529-533.

19. Ominsky MS, et al. Two doses of sclerostin antibody in cynomolgus monkeys increases bone formation, bone mineral density, and bone strength. J Bone Miner Res. 2010;25(5):948-959.

20. Ominsky MS, et al. Romosozumab improves bone mass and strength while maintaining bone quality in ovariectomized cynomolgus monkeys. J Bone Miner Res. 2017;32(4):788-801.

21. Cosman F, et al. Romosozumab treatment in postmenopausal women with osteoporosis. N Engl J Med. 2016;375(16):1532-1543

22. McClung MR, et al. Romosozumab in postmenopausal women with low bone mineral density. N Engl J Med. 2014;370(5):412-420.

23. Zhang Y, et al. The LRP5 high-bone-mass G171V mutation disrupts LRP5 interaction with Mesd. Mol Cell Biol. 2004;24(11):4677-4684.

24. Ai M, Holmen SL, Van Hul W, Williams BO, Warman ML. Reduced affinity to and inhibition by DKK1 form a common mechanism by which high bone mass-associated missense mutations in LRP5 affect canonical Wnt signaling. Mol Cell Biol. 2005;25(12):4946-4955.

25. Semënov MV, Tamai K, Brott BK, Kühl M, Sokol S, He X. Head inducer Dickkopf-1 is a ligand for Wnt coreceptor LRP6. Curr Biol. 2001;11(12):951-961.

26. Bourhis E, et al. Reconstitution of a frizzled8.Wnt3a.LRP6 signaling complex reveals multiple Wnt and Dkk1 binding sites on LRP6. J Biol Chem. 2010;285(12):9172-9179.

27. Mukhopadhyay M, et al. Dickkopf1 is required for embryonic head induction and limb morphogenesis in the mouse. Dev Cell. 2001;1(3):423-434.

28. MacDonald BT, Adamska M, Meisler MH. Hypomorphic expression of Dkk1 in the doubleridge mouse: dose dependence and compensatory interactions with Lrp6. Development. 2004;131(11):2543-2552.

29. MacDonald BT, et al. Bone mass is inversely proportional to Dkk1 levels in mice. Bone. 2007;41(3):331-339

30. Li X, et al. Dickkopf-1 regulates bone formation in young growing rodents and upon traumatic injury. J Bone Miner Res. 2011;26(11):2610-2621.

31. Balemans W, et al. The binding between sclerostin and LRP5 is altered by DKK1 and by high-bone mass LRP5 mutations. Calcif Tissue Int. 2008;82(6):445-453.

32. van Lierop AH, Moester MJ, Hamdy NA, Papapoulos SE. Serum Dickkopf 1 levels in sclerostin deficiency. J Clin Endocrinol Metab. 2014;99(2):E252-E256.

33. Florio M, et al. A bispecific antibody targeting sclerostin and DKK-1 promotes bone mass accrual and fracture repair. Nat Commun. 2016;7:11505.

34. Stolina M, et al. Temporal changes in systemic and local expression of bone turnover markers during six months of sclerostin antibody administration to ovariectomized rats. Bone. 2014;67:305-313.

35. Brunkow ME, et al. Disruption of a new forkhead/winged-helix protein, scurfin, results in the fatal lymphoproliferative disorder of the scurfy mouse. Nat Genet. 2001;27(1):68-73.

36. van Lierop AH, Hamdy NA, van Egmond ME, Bakker E, Dikkers FG, Papapoulos SE. Van Buchem disease: clinical, biochemical, and densitometric features of patients and disease carriers. J Bone Miner Res. 2013;28(4):848-854.

37. van Lierop AH, et al. Patients with sclerosteosis and disease carriers: human models of the effect of sclerostin on bone turnover J Bone Miner Res. 2011;26(12):2804-2811.

38. Ross RD, et al. HBM Mice have altered bone matrix composition and improved material toughness. Calcif Tissue Int 2016;99(4):384-395

39. Hassler N, et al. Sclerostin deficiency is linked to altered bone composition. J Bone Miner Res. 2014;29(10):2144-2151.

40. Boudin E, et al. The Lrp4R1170Q homozygous knock-in mouse recapitulates the bone phenotype of sclerosteosis in humans. J Bone Miner Res. 2017;32(8):1739-1749.

41. Cui Y, et al. Lrp5 functions in bone to regulate bone mass. Nat Med. 2011;17(6):684-691.

42. Pflanz D, et al. Sost deficiency led to a greater cortical bone formation response to mechanical loading and altered gene expression. Sci Rep. 2017;7(1):9435

43. Economides AN, et al. Conditionals by inversion provide a universal method for the generation of conditional alleles. Proc Natl Acad Sci USA. 2013;110(34):E3179-E3188.

44. Leupin O, et al. Bone overgrowth-associated mutations in the LRP4 gene impair sclerostin facilitator function. J Biol Chem. 2011;286(22):19489-19500.

45. Choi HY, Dieckmann M, Herz J, Niemeier A. Lrp4, a novel receptor for Dickkopf 1 and sclerostin, is expressed by osteoblasts and regulates bone growth and turnover in vivo. PLOS ONE. 2009;4(11):e7930.

46. Niziolek PJ, et al. High bone mass-causing mutant LRP5 receptors are resistant to endogenous inhibitors in vivo. J Bone Miner Res. 2015;30(10):1822-1830

47. Yorgan TA, et al. The anti-osteoanabolic function of sclerostin is blunted in mice carrying a high bone mass mutation of Lrp5 J Bone Miner Res. 2015;30(7):1175-1183. 
48. Li J, et al. Dkk1-mediated inhibition of Wnt signaling in bone results in osteopenia. Bone. 2006;39(4):754-766.

49. Paic F, et al. Identification of differentially expressed genes between osteoblasts and osteocytes. Bone. 2009;45(4):682-692.

50. Taylor S, et al. Time-dependent cellular and transcriptional changes in the osteoblast lineage associated with sclerostin antibody treatment in ovariectomized rats. Bone. 2016;84:148-159.

51. Komatsu DE, Mary MN, Schroeder RJ, Robling AG, Turner CH, Warden SJ. Modulation of Wnt signaling influences fracture repair. J Orthop Res. 2010;28(7):928-936.

52. Yaccoby S, Ling W, Zhan F, Walker R, Barlogie B, Shaughnessy JD. Antibody-based inhibition of DKK1 suppresses tumor-induced bone resorption and multiple myeloma growth in vivo. Blood. 2007;109(5):2106-2111.

53. D'Amico L, et al. Dickkopf-related protein 1 (Dkk1) regulates the accumulation and function of myeloid derived suppressor cells in cancer. J Exp Med. 2016;213(5):827-840.

54. Diarra D, et al. Dickkopf-1 is a master regulator of joint remodeling. Nat Med. 2007;13(2):156-163.

55. Heiland GR, et al. Neutralisation of Dkk-1 protects from systemic bone loss during inflammation and reduces sclerostin expression. Ann Rheum Dis. 2010;69(12):2152-2159.

56. Yang F, Tang W, So S, de Crombrugghe B, Zhang C. Sclerostin is a direct target of osteoblast-specific transcription factor osterix. Biochem Biophys Res Commun. 2010;400(4):684-688.

57. Sutherland MK, Geoghegan JC, Yu C, Winkler DG, Latham JA. Unique regulation of SOST, the sclerosteosis gene, by BMPs and steroid hormones in human osteoblasts. Bone. 2004;35(2):448-454.

58. Loots GG, Keller H, Leupin O, Murugesh D, Collette NM, Genetos DC. TGF- $\beta$ regulates sclerostin expression via the ECR5 enhancer. Bone. 2012;50(3):663-669.

59. Wein MN, et al. HDAC5 controls MEF2C-driven sclerostin expression in osteocytes. J Bone Miner Res. 2015;30(3):400-411.

60. Keller H, Kneissel M. SOST is a target gene for PTH in bone. Bone. 2005;37(2):148-158.

61. Genetos DC, et al. Hypoxia decreases sclerostin expression and increases Wnt signaling in osteoblasts. J Cell Biochem. 2010;110(2):457-467.

62. Sebastian A, Loots GG. Transcriptional control of Sost in bone. Bone. 2017;96:76-84.

63. Kamiya N, et al. Wnt inhibitors Dkk1 and Sost are downstream targets of BMP signaling through the type IA receptor (BMPRIA) in osteoblasts. J Bone Miner Res. 2010;25(2):200-210.

64. Zhang C, Dai H, de Crombrugghe B. Characterization of Dkk1 gene regulation by the osteoblast-specific transcription factor Osx. Biochem Biophys Res Commun. 2012;420(4):782-786.

65. Collette NM, et al. Sostdc1 deficiency accelerates fracture healing by promoting the expansion of periosteal mesenchymal stem cells. Bone. 2016;88:20-30

66. Kiper POS, et al. Cortical-bone fragility--insights from sfrp4 deficiency in Pyle's disease. N Engl J Med. 2016;374(26):2553-2562.

67. Brommage R. Genetic approaches to identifying novel osteoporosis drug targets. J Cell Biochem. 2015;116(10):2139-2145 .

68. Holdsworth G, et al. Dampening of the bone formation response following repeat dosing with sclerostin antibody in mice is associated with up-regulation of Wnt antagonists. Bone. 2018;107:93-103.

69. Pietilä I, et al. Secreted Wnt antagonist Dickkopf-1 controls kidney papilla development coordinated by Wnt-7b signalling. Dev Biol. 2011;353(1):50-60.

70. Lu Y, Xie Y, Zhang S, Dusevich V, Bonewald LF, Feng JQ. DMP1-targeted Cre expression in odontoblasts and osteocytes. $J$ Dent Res. 2007;86(4):320-325

71. Niziolek PJ, Farmer TL, Cui Y, Turner CH, Warman ML, Robling AG. High-bone-mass-producing mutations in the Wnt signaling pathway result in distinct skeletal phenotypes. Bone. 2011;49(5):1010-1019.

72. Robling AG, et al. Anabolic and catabolic regimens of human parathyroid hormone 1-34 elicit bone- and envelope-specific attenuation of skeletal effects in Sost-deficient mice. Endocrinology. 2011;152(8):2963-2975.

73. Bouxsein ML, Boyd SK, Christiansen BA, Guldberg RE, Jepsen KJ, Müller R. Guidelines for assessment of bone microstructure in rodents using micro-computed tomography. J Bone Miner Res. 2010;25(7):1468-1486.

74. Robling AG, et al. Sost, independent of the non-coding enhancer ECR5, is required for bone mechanoadaptation. Bone. 2016;92:180-188.

75. Dempster DW, et al. Standardized nomenclature, symbols, and units for bone histomorphometry: a 2012 update of the report of the ASBMR Histomorphometry Nomenclature Committee. J Bone Miner Res. 2013;28(1):2-17.

76. Turner CH, Burr DB. Basic biomechanical measurements of bone: a tutorial. Bone. 1993;14(4):595-608.

77. Robling AG, et al. Mechanical stimulation of bone in vivo reduces osteocyte expression of Sost/sclerostin. J Biol Chem. 2008;283(9):5866-5875.

78. Ross RD, Mashiatulla M, Robling AG, Miller LM, Sumner DR. Bone matrix composition following PTH treatment is not dependent on sclerostin status. Calcif Tissue Int. 2016;98(2):149-157.

79. Acerbo AS, Carr GL, Judex S, Miller LM. Imaging the material properties of bone specimens using reflection-based infrared microspectroscopy. Anal Chem. 2012;84(8):3607-3613. 